\title{
Pre-Service Teachers in the Outdoors: A Phenomenological Exploration
}

\author{
Josie Melton, Western Washington University, USA \\ Email: josie_melton@wwu.edu
}

\section{Abstract}

While a child's sense of wonder is thought to come naturally, less is known about how adults foster or connect with their sense of wonder. For the purposes of this exploration, wonder is the openness that comes when one dwells with the present moment, allowing questions to arise, rather than using wonder as a tool to answer a question (Gadamer, 2004; van Manen, 2014). Spending time in the outdoors is a common way to engage wonder, but there may be differences in the ways adults experience their surroundings compared to children. If teachers or parents aim to foster a child's sense of wonder then it is important to understand how adults experience and connect to the outdoors so they can model and promote the connection for children. This paper explores the experiences of adults in the outdoors in order to better understand the barriers and paths that may lead

to wonder. Five anecdotes from outdoor experiences are phenomenologically analyzed to better understand the lived experience of adults in the outdoors. Themes from the anecdotes are discussed, as well as the implications for teacher education programs.

Keywords: wonder, preservice teachers, environmental education

\section{Introduction}

Asking questions and identifying problems is a skill we expect children to apply in science education (NRC, 2012). If this is a goal, then cultivating a similar awareness and practice in adults can be considered an important piece of teacher education. Unfortunately, adults may not question and wonder as naturally as children. Carson (1998) describes the need for re-connecting adults with their sense of wonder:

A child's world is fresh and new and beautiful, full of wonder and excitement. It is our misfortune that for most of us that clear-eyed vision, that true instinct for what is beautiful and awe-inspiring, is dimmed and even lost before we reach adulthood. (p. 54)

In order to gain a deeper understanding of how we can re-connect adults with their own questions and wonder, it is important to learn more about how adults experience the outdoors. Specifically, what is the experience of adults in the outdoors and what might present challenges to wonder? This discussion explores the experiences of five adults alone in an outdoor setting in hopes of learning more about the relationship between feelings of wonder and outdoor natural phenomena and how a phenomenological interpretation of these lived experiences may provide insights for working with children. 


\section{What is Wonder?}

Wonder is defined by the Online Reference Dictionary as "To think or speculate curiously; to be filled with admiration, amazement, awe" but many believe that a child's sense of wonder goes beyond the dictionary's description. To have a "sense of wonder" is more than being curious. Someone can be curious and relieve their curiosity by seeking an answer to a question, but wonder is something more. Gadamer (2004) explains "Socrates teaches that the important thing is the knowledge that one does not know" (p. 359). Here Gadamer (2004) downplays the importance of how much you know, and builds to the idea that the most important knowledge is what you seek to know. For Gadamer (2004) this is about ideas that: "always presuppose an orientation toward an area of openness from which the idea can occur - i.e., they presuppose questions" (p. 359). Clearly, Gadamer is referring to the sense of wonder, a dwelling in the openness that emphasizes the questioning more than the solution. The knowledge that you do not know is where wonder begins.

Van Manen (2014) urges people to engage in wonder by avoiding an active seeking in response to a question, but by allowing wonder to seek you. In order to gain knowledge, he believes you must be intentionally open to the world as it presents itself. Heidegger (1994) also believes that a relationship exists between wonder and knowledge, and by exploring the concept of wonder he refers to thaumazein, or wonder, as a "basic disposition -one that transports into the beginning of genuine thinking and thoroughly determines it" (p.136). Heidegger (1994) states: "In wonder what is most usual itself becomes the most unusual" (p. 144). Thus, wonder is dwelling in the familiar rather taking it all for granted. Compiling the ideas of Gadamer, van Manen, and Heidegger, we may say that to experience wonder, one should focus on the present moment and hold a space, or openness for whatever may come. So what does this have to do with elementary science classrooms? The outdoors can be rich source of wonderment and a site for scientific exploration of all ages.

Why is outdoors a source of wonder? And do children live this wonderment differently from their teachers? These questions are raised due to the following: children are thought to "lose interest in the 'why and how' of the world as they are fed other people's ideas during hours and hours of TV watching" (Russell, 2001, p. 9). Therefore, from an educator's stance it seems important that teachers reconnect students with their natural surroundings. A shift is needed for adults, teachers specifically, to guide students to dwell in the openness of the present moment, as Gadamer (2004) describes it. Aoki (2004) observes that teachers already dwell "in the zone of between" (p. 161) as they navigate the middle ground of the planned and lived curriculum, harnessing the tensionality of the unknown to respond to the needs of their students. Could this same practice be used to guide children to navigate the tensionality of the unknown while dwelling in the outdoors? Before we can ask classroom teachers to guide children to cultivate or maintain their connection with nature, there may be value in re-exposing inservice and preservice teachers to the outdoors to learn more about their own experiences. For this discussion, how adults experience a re-kindling of wonder is of particular interest. 


\section{Methodology}

Phenomenology can be used to examine the way a person experiences the lifeworld. Existential phenomenology uses anecdotes, or descriptions of a participant's experience, as a tool to understand their unique perception of a phenomenon in the lifeworld. In order to stay true to the participant's lifeworld experience of prereflective moments, van Manen (2014) values the epoché, or the idea that we need to free ourselves from presuppositions in order to open ourselves to the world. Phenomenology in practice attempts to bracket the views of the researcher so that the phenomenon can be represented as experienced by the participant, and the main purpose of the reduction is to gain access "to the world of prereflective experience -as-lived in order to mine its meanings" (van Manen, 2014, p. 221). In this way, findings are reached through hermeneutical analysis of the experience as-lived and perceived by the participant, rather than through the reflective lens of the researcher. Thus, hermeneutic phenomenology assumes that all phenomena present themselves in a way that only allows one particular view or aspect (van Manen, 2014); that the relationship between participant and phenomenon is unique. The goal is to represent that phenomenon as the way it appears to the participant's consciousness, or to show their way of being at that particular time in carefully written anecdotes.

For this discussion, I will share moments of wonder, as lived experiences by preservice teachers taking my course. This data has Research Ethics approval and the involved participants provided consent to use their written work for this paper as part of a larger study. Specifically, for this discussion, the lived experience descriptions are in the form of anecdotes to provide glimpses into preservice teachers' experiences in an outdoor setting. Each anecdote was created by the participant and has been edited by the researcher to bracket the experience and emphasize lived moments described by the participants. Therefore, each anecdote is based on an actual outdoor experience, and through the process of bracketing, and hermeneutical reflection, provides reflective insight into the challenges and affordances of adults connecting to their sense of wonder in an outdoor setting. Five participant experiences are presented: my own plus four preservice teacher anecdotes, in which participant names have been changed to ensure confidentiality. The anecdotes are thematically discussed in comparison to each other, and to relevant literature.

Phenomenology is often used as a qualitative lens to examine humans' relationship with the natural environment (Howarth, 1995; Thorburn \& Marshall, 2014; van der Schyff, 2010), and in particular for educators engaging children in outdoor settings (Foran \& Saevi, 2012; Foran \& Olson, 2012; Foran, 2008A; Foran, 2008B; Foran, 2005). Applying Heidegger's (1996) notion of dwelling in the world enables phenomenology to better understand how people perceive nature. Howarth (1995) explains that it is the combination of holistic mind-body perception and dwelling as a way of being in the world that allows phenomenology to recognize how people perceive experiences and values. Van der Schyff (2010) contributes to this discussion by adding that the role of modern technology may overshadow ecological consciousness. He believes phenomenology could provide insights into the true human way of being by offering a "philosophical perspective that may aid us in clearing away the noise of culture, civilization and technology so that we might experience nature and ourselves in a 
more direct way" (p. 117). Thus, phenomenology is a useful methodology to examine issues of ecology and environmentalism, or in this case, the experience of preservice teachers in an outdoor setting.

\section{How do I Experience Wonder in an Outdoor Setting?}

Existing phenomenological studies explore the experience of humans engaging in specific activities in natural environments, such as exercising, or engaging with students, or older people's experiences in nature (Allen-Collinson \& Leledaki, 2015; Foran \& Saevi, 2012; Foran \& Olson, 2012; Foran, 2008A; Foran, 2008B; Foran, 2005; Orr, Wagstaffe, Briscoe \& Garside, 2016) but there are limited descriptions of the experience of adults simply spending time alone outside. Focusing on this phenomenon could help us understand precisely what adults experience when attempting to connect with the natural environment, and whether those experiences lead to dwelling in the present moment, and an openness to what may come. This discussion is specifically focused on how adults engage with the natural world outdoors, and whether such experiences could lead to wonder, and what the experience of wonder is for adults.

Learning how adults connect with the outdoors can help teacher educators understand how to prepare teachers to lead students in wonderment activities. Guiding students to engage their own wonder outdoors may provide a different pedagogical intensity (Foran, 2005), one which classroom teachers may not be familiar with. If preservice and classroom teachers are expected to engage in wonder outdoors, along with their students, then it is important to understand how teachers experience natural settings by accessing the prereflective experience of wonder. To learn about how pre-service teachers experience the outdoors, I designed the following exercise as part of an elementary science methods course:

Spend 20-30 minutes alone in nature: No technology, no company, no distractions. Use all of your senses to observe your surroundings in the present moment. Write a 1-2 page description of your experience.

I completed the task myself prior to assigning it to my students, and the following anecdote is from my own experience.

I close my eyes; the smell of moist earth immediately fills my nostrils, then spreads slowly through my body like a wave. The leaves around me crinkle with movement although I lay perfectly still, a cup of tea resting warm and motionless between my knees. My body is supported by foliage; brown sticks and green stems and ferns are crushed under my weight yet prop me above the damp dirt, providing a barrier from the moisture in the earth. I visualize tiny bugs creeping all around the otherwise still area around me - their legs and bodies shifting the earth and the leaves around them. I imagine the decaying of downed trees and leaves whose odor and presence fill this forest, and the bugs busily chewing away at the flesh of rotting logs and trunks.

Alone in the woods, I find it easy to forget the stresses of everyday life and focus on my surroundings. When I first close my eyes, the distinct smell of mature 
evergreen forest overpowers all other senses and I notice only what is directly around me. My mind then turns to the sounds of the forest and I hear the movement of leaves crinkling, and realize it is not me causing the rustling. My body feels supported by 'sticks and ferns' of the earth, and in my stillness, I can imagine with my mind's eye the movement of the world around me. I am held in stillness and my mind focuses on the restless insects of the woods. And in this stillness, I reach clarity and I can freely wonder: what are these smells, what are these noises, what am I seeing on the spotlight of sun between the shadows, what am I feeling where my body touches the earth? I am free of my day to day tasks and worries and the busyness of my surroundings replaces my normally busy body and mind, allowing my mind to move more slowly, and softly. Like the life all around me, I begin to dwell in the woods, rather than in my humancentered world, which allows me to wonder.

I notice the healthy Douglas fir trees surrounding me, their brown branches with green needles shielding me from the rain, and I wonder how long until those trees turn soft. I picture the cycle of life - young trees growing, falling, decomposing, and all of the organisms that are impacted by this cycle. How many organisms have lived in this forest? How many organisms are here, touching the same soil as me, right now? If I die here, how long before my body is reduced to nutrients, also returned to the earth? An airplane roars in the distance and I am jolted to the present moment. How long have I been lying here?

The trees above me are shielding me from the rain, but I begin thinking about how long they will continue to provide this majestic canopy. Thinking about the tree and how it will eventually break down leads me to wonder about the cycle that is occurring all around me: life, death, decomposition, and back to life. One question gently leads to another without disruption as I simply follow the thoughts that race through my mind, not waiting for an answer, just like they did as a child exploring the world. I peacefully recognize that everything here will eventually be subject to decay, including my own body. I actually lose track of time as my mind wanders and explores the intricacies of the cycle of life. I no longer feel I am in the woods, digesting the progressing cycle of life. I feel like I am a part of the woods, like I belong.

This feeling of belonging that settled within me as I wondered about my surroundings is also a useful measure of one's connectedness to nature (Mayer \& McPherson Frantz, 2004). Could dwelling in wonder increase one's affinity for the outdoors? Heidegger (1996) compares dwelling with an idea with dwelling where one lives. Howarth (1995) furthered this analogy by elaborating on the concept of dwelling. When one dwells in a home, they create a place for themselves: A dip in the cushion of the favorite seat on a couch, a barer spot on the material covering a favorite armchair, for example. Similarly, when people dwell in wonder, they may find a comfortable place in their thoughts to stay a while, contemplating whatever may arrive. Or they may wander, this is a liberating experience, without confines or boundaries. Feelings of freedom and comfort may facilitate a belonging in the place where they wonder, further connecting them to the outdoors. Is a natural sense of belonging in the outdoors why children wonder more freely? 
This feeling of connectedness comes easily to me when my senses are in tune with my rich surroundings. With my eyes closed, I tune into my sense of touch, smell, sight, and hearing, which pauses the present moment until the airplane interrupts my thoughts. When the mechanical sounds of the plane fill my ears, I struggle with the space in-between the natural and human worlds, as if I am prematurely jolted back to the present moment. Returning to Aoki's (2004) conception of dwelling in the space between, I am not able to maintain a connection to the outdoors when I am exposed simultaneously to the natural world of the outdoors and the human-world. The juxtaposition of the airplane roaring in my ears with along with the sounds and impressions of my immediate surroundings abruptly ends my relation to the woods, like a phone connection might be lost mid-conversation. It takes me a couple of minutes to be present with the human world.

The airplane noise fades, and I sit up to see two women walking along the trail below me, beside a lake. One of the women looks up, surprised, and I look nervously away. I take a sip of tea, which is now cold on my tongue and gaze out at the lake, trying to look natural, like I belong in the woods. A black ducklike bird pops up in the middle of the lake and I wonder 'Where did it come from? How long has it been there? What was it doing below the surface?' I am suddenly aware of the women watching me watch the birds. I wonder if they are thinking the same about me-popping up in the middle of the woods. Do they think it is weird that I was laying in the woods? The birds didn't care who was watching them. Why can't I be like the birds, immune to the judgmental stares of others? The walkers leave my peripheral vision and I am relieved that they are gone. Though my connection to this place is gone, too.

When I first sit up and realize that the women can see me, I try to ignore their glances and focus again on my senses. The birds in the lake capture my attention but the women's presence distracts me from my observations. When the women notice me, I feel embarrassed - as if I were caught doing something socially unacceptable. I return to the norms of my everyday human life, lured out of my wondering stance. The women's eyes signal that maybe I am out of place, although I felt like I belonged. I try to carry on as if it is ordinary, and while avoiding eye contact with the women, I try to return to the birds in the lake, but now it is different. I find a similarity between my own behavior and the birds and I am surprised by my own social insecurities. It feels natural to be in the woods watching the birds, though the women who watch me seem to think otherwise.

Outside distractions break my focus on the natural world around me in both instances. The mechanical sound of the airplane contrasts so glaringly with my peaceful vision of the life cycle that I am thrown back to "reality."

Did modern day technological advances disconnect me from my natural surroundings, as Van der Schyff (2010) predicted? Heidegger (1977) addressed the destructive relationship between humans and technology. James (2002) further explains Heidegger's stance: "Heidegger maintains that the dominance of the technological understanding of the world manifests itself as an estrangement from the world, an existential sense of homelessness" (p. 2). This interpretation places a strong dualism between technology and the natural, outdoor environment. The mere presence of technology may create a dissonance or tensionality between humans and the world, especially the natural world. 
This explains the jarring effect the plane had on my peaceful observation, and openness to my natural outdoor environment.

The glances of the women also interrupted my concentrated observation of the birds on the lake. When the women see me, their perception of me overshadows my feelings of comfort and belonging. These outside interruptions in the presence of nature could pose challenges for adults to focus on their senses and be in the present moment. I wonder whether these outside distractions are what prevent adults from being open to the world in the way children are? Is wondering only possible when adults are relieved of their everydayness; when the mind, or consciousness can let go? This tensionality between everyday distractions and complete openness is Aoki's "Zone of Between" (2004) and could help us understand how adults experience the outdoors.

\section{Adults Outdoors}

To gain insight in how other adults connect with their wonderment in outdoor surroundings, I provided the same opportunity for my class of preservice teachers. The following are anecdotes drawn from my students' written work when asked to describe their own experiences alone in an outdoor setting:

I close my eyes to get in touch with my surroundings. I hear a rustling, then a snapping sound and quickly open my eyes, turning towards the sounds. There might be another person nearby. I am anxious being alone; I wonder if the experience of being alone in the woods is different for women compared to men. Women are physically more vulnerable when they are alone. Is that why I am so uncomfortable? The noisy dialogue in my head makes it difficult to focus on my senses. It is not an overwhelming feeling of anxiety, just an acute awareness of my vulnerability. (Kelley)

Kelley chose to close her eyes and focus on her other senses to better experience her environment, but this actually had the opposite effect. With her eyes closed, the sounds of nature were alarming since she could not see what was producing them. She had some anxiety about being alone in the woods so rather than focusing on her body in the present moment, Kelley focused on her isolation and on feelings of vulnerability while alone in a wooded area. Did the lack of technology in this environment add to Kelley's anxiety? Kelley's discomfort did not stem from a human-caused disruption, rather it was the assumption that natural sounds were caused by humans that created anxiety. This anxiety prevented her from dwelling in the outdoors and created a barrier to her sense of wonder.

Following Heidegger's (1977) line of thinking, could it be that Kelley's comfort in the presence of technology displaced her in the outdoors? Despite our different reactions to sounds during our observation, her experience is similar to my experience in that we were both distracted by unnatural, human-caused phenomena, which prevented us from focusing on our surroundings. It is not until 
Kelley consciously pushes aside the distracting thoughts that she can identify other sounds around her.

I close my eyes to listen, again focusing on my senses. I hear the call of a Spotted Towhee, and a Crow, joined by other songbirds whose names I've never learned. I hear some large flies or bees buzzing near my head. I hear the drone of the freeway in the distance; it almost sounds like a raging river or waterfall. I then notice the sound of a car driving along the road that winds through the Arboretum and I wonder if I had picked a "wild" enough place. (Kelley)

When Kelley closed her eyes to re-focus, she was able to recognize the calls of birds, some of which were familiar and some not. Attending to the bird calls allowed Kelley to become attuned to her immediate surroundings, and she left her thoughts of vulnerability until she was interrupted by a different sound. This time it was a sound that was out of place in the woods - a sound that again reminded her of her proximity to humans. The sound of a car brought her thoughts out of the woods, back to 'civilization', and possibly to a place she subconsciously wished to return.

Both Kelley's and my own experience highlight a theme of distractions from civilization disrupting a concentration on what the body was experiencing in the outdoors at that time. This could be due to the draw toward the everydayness of the human world, where most adults spend the majority of their time and thought. In my own experience, I found myself content to absorb my surroundings through all of my senses until the sound of the jet-plane, and the women on the trail interrupted my flow of thought. Similarly, it was the thought of other people in Kelly's space that prevented her from focusing on her surroundings. Research shows that fear, and human faces create a strong distraction to concentration (Parks, Kim, \& Hopfinger, 2014), explaining our abrupt break in focus. But even after Kelley rid herself of the unsettling thoughts and concentrated on the birds, it was the sound of cars that ultimately pulled her attention away from the sounds of the birds. This draw away from her natural surroundings prevented Kelley from being open to experiencing her immediate senses, and thus may have prevented her from engaging in wonder. Kelley was ultimately unable to dwell in the place between the human and natural worlds.

However, not all distractions in the outdoors are a result of human presence. In the next anecdote, Erica describes some different challenges she experienced while trying to focus on her surroundings at a local park:

At the beginning, I am impatient-the impulse to check the time makes it impossible to tune into my senses. I look at my wrist for a watch that isn't there and feel my pocket for an absent phone. But by the end, I actually find myself wishing I could stay longer, and I wonder why I have not done this before. Eventually, my thoughts wander to the future and what I need at the grocery store, what other homework I have to complete. I try to clear my mind so that I can focus on being here in the present. I inhale the 
fresh, cold air deeply, and sigh noisily. This task proved to be harder than I thought. (Erica)

Erica describes how she had difficulties settling into the experience and notes that at first, time seemed to pass slowly. She was initially impatient, but by the end of the experience her perception has shifted, and she wants time to slow down. She recognizes that her mind wanders, attending to her daily responsibilities and to-do list, but she makes a conscious effort to return to wonder, to focus on the present and her senses. She is strongly pulled back to the civilized world where she lives most of the time, but is aware of the tensionality between the two.

By connecting with her body and how she feels at that moment, Erica is able focus on being in the present. Although difficult, Erica recognizes that focusing on what is happening in the "here and now" enables her to be aware of her senses in the moment, and not be distracted by her responsibilities. MerleauPonty (1962) believes that prior knowledge and experiences determine how one perceives the present moment, and Kelley's anxiety about her daily life is affecting her experience in the outdoors. She attempts to ignore her prior knowledge and experiences by putting them aside and bringing current sensory information to the forefront. It is not uncommon for adults to be too caught up in their daily responsibilities and worries to experience the present moment, and it is a relatively under-researched area of attention within psychology (Forster \& Lavie, 2014). Attending to sensory experiences as they are happening may make it easier to avoid distracting thoughts. What happens to a person's experience when they are able to tune out those distractions from the civilized human world? How does that change their experience outside?

The following excerpt describes a new experience in the woods. At this point, Jesse's obligatory 30 minutes for the assignment are up, but as she begins to get up from the rock she sits on, something catches her attention.

I reach out and touch the moss surrounding me. It is soft, yet textured-not silky smooth as I thought. There are little malleable spikes poking off of it. I give into a childlike impulse and roll onto my belly to get as close as I can to the moss. I rest my chin on the sharp, cold rock and gaze into the moss. It is almost like a forest itself. There are little branches growing out of the clump, and each branch has a number of green swords poking off of it. I have been surrounded by moss for years and I have never taken the time to study it. Why does it grow in this way? How many different types are there? What is the difference between lichen and moss? I tilt my nose down and take a quick sniff and then a few more. The moss does not have a specific smell, but the wet earth surrounding the rock is musty, yet fresh. (Jessie)

In close proximity to the rock, Jessie is able to utilize all of her senses to fully experience the moss she sat on. This intense engagement with senses may lead to dwelling in the present moment, thus resulting in wonder. She touches the moss around her and is surprised to find it different than she expected. Her 
intrinsic motivation in the moss allows her to focus all of her attention on all she can observe about the moss. She gets down to observe the moss at eye-level and is amazed to find that it resembles a tiny forest. Jessie recognizes that moss is something that she has seen for most her life, but she has never thought to examine it up close. She is surprised by this newfound interest in something so usual. With no interruptions, her mind swirls with questions about moss, one leading to the next. Rather than consider the answers to her questions, she gets even closer, to utilize another sense - her sense of smell. She dwells with the moss, slowing down and creating room in time and space to consider more questions.

Jessie is open to whatever comes to her without a need to answer the questions. This openness is a precursor to wonder, an entrance to the circle of questions, which Jessie finds enjoyable. Like Gadamer, by dwelling with the knowledge she doesn't know, she is drawn toward true wonder. Her ability to focus on her senses is an interesting contrast to the disruptions described in the previous anecdotes. In this situation, when Jesse's questions come to her, she is not interrupted by distracting sounds or internal thoughts, but she is mentally relaxed and able to maintain focus on what is happening around her. Could this be the pre-requisite for adults to experience openness and thus, wonder about the world?

It seems that children are not distracted by the seemingly endless list of things that need to get done, are not uncomfortable in social situations, and do not have the life experience that may distract an adult from the world around them. Children are building their understanding as they go, and it is this naïve approach to life that may allow them to live in the present moment and be in touch with their senses more readily than adults. The lifeworld approach to nature says that children develop their own views about the environment through personal experience (Hung \& Stables, 2008). This supports the idea that children are less distracted by external stimulus and thoughts since they are still constructing their understanding of the differences between the natural and human worlds. If this is true, then could this be why adults do not experience a sense of wonder as readily as children do? Is limiting the human-world interruptions the key to nurturing a sense of wonder in adults so that they can more easily focus on their senses in the present moment? Could this help teachers experience a sense of wonder and connect with nature in an authentic way so they can provide guidance for students to retain their openness to wonder for as long as possible?

Like Jessie, Melanie's experience also illustrates what it is like to experience one's senses without any interruptions. She is totally immersed in what is happening around her on the beach, limiting all distracting thoughts:

Every once in a while, there is a large gust of wind that howls past my ears, numbing my earlobes and moving my loose hair. Between the howling wind and the crashing white waves, I cannot hear anything else. I enjoy the solidarity of not being bothered or distracted by other sounds. The endless sets of waves roll in, churning one after another on the sand. I 
wonder to myself, "do the waves ever stop coming in?" I turn away from the water and notice a great contrast of yellow-brown against the steelygray tones of sand behind me. Different sized pieces of driftwood comprises this yellow-brown band creates a border between sand and vegetation. Some logs along the band are so massive that I can't help to wonder, "what storm was so powerful to push that tree trunk up there?" (Melanie)

By allowing the sound of the wind and waves to drown out all other sounds, Melanie, too, is better able to concentrate on her surroundings. She recognizes that the isolation from distracting sounds helps her focus on the beach scene in front of her. This concentration on the natural phenomena and lack of distractions from the human-world allow Melanie to be open to many wonders about what she is observing. Isolated on the beach, with waves and wind blocking out any reminder of technology, she is drawn to wonder by an awe of a somewhat usual beach scene.

The persistence of the waves, a phenomenon that she has probably witnessed many times before, leads to many questions, and she takes special note of a tree trunk up the beach. Being in touch with the present moment through her senses creates an openness that enables Melanie's mind to wander to questions to which she does not need an immediate answer, but to questions that allow her to appreciate the extra-ordinary in some otherwise ordinary features of a beach.

Melanie recognizes that it was the freedom from her life-world that allowed her to be "in the moment". Not only did Melanie's focus on her surroundings allow her to disconnect from outside responsibilities and distraction, but she was also comfortable alone on an uninhabited beach. These conditions (an ability to focus on senses, limited human-world distractions, and feeling physically safe) were present in all experiences where adults were in touch with a sense of wonder or were open enough to recognize the extra-ordinary in the ordinary.

\section{Implications for the Science Classroom}

All of these excerpts provide insight into the conditions that inhibit or facilitate an openness to one's natural surroundings. The ability to commit full attention to the present moment in order to let this openness arise is what van Manen referred to as an 'active-passive receptivity' that seems to occur without outside distractions. Distractions from human-related noises or thoughts about issues of daily life in civilization prevented participants from experiencing wonder. Given minimal human-world distractions and an internal awareness of the senses, the questions that arise with no need for an answer is where wonder exists - the emphasis of the question over the answer.

Identifying the conditions that may lead to a sense of wonder in adults has implications for how teachers guide children to cultivate or maintain their sense of 
wonder. Minimizing human-world interruptions and focusing on the senses are two factors that may lead to adults experiencing a sense of wonder in the outdoors. Allowing teachers to experience a sense of wonder and model that state of being for students in the classroom could offset the effects of children's increasing screen time and limited outdoor exposure. Could this shift in practice encourage children to retain their wonder of, and appreciation for nature? On his website, Buddhist ecologist Thich Nhat Hahn (2015) says "Only when we recognize our connectedness to the earth, can real change begin." He believes that improving humans' relationship with the Earth can begin with a feeling of connectedness. Researchers, too, identify this feeling of connectedness as a measure of one's relationship to nature (Mayer \& McPherson Frantz, 2004). This implies that arming teachers with strategies to connect children with their sense of wonder could promote an ethic of care and action for the environment.

Re-living and embodying this wonder and openness toward nature may be the key to nurturing the awareness and awe that children naturally bring to the classroom. The goal should not be for teachers to show that they 'know it all' but to show that, like Socrates, they value that which is not known. Maybe we can challenge each other to not dismiss a child's question with a quick answer, as we might sometimes be tempted to do, but rather to notice, dwell with, and appreciate the extra-ordinariness of the phenomena in question. Teachers are expected to lead, and in promoting wonder, a quiet leadership can emerge. As Aoki (1993) points out, the Chinese characters of a wise leader translate to "a person who, indwelling with others, stands between heaven and earth, listening to the silence, and who, upon hearing the word, allows it to speak to others so others may follow." (p. 267). Similarly, in outdoor settings wise teachers may experience the tensionality of the place in between, attend to their senses, and bring awareness to the unknown. Wise leaders lead by example, and by modeling how to allow questions to be revealed to them, teachers are promoting a sense of wonder. Wise teachers do not share their wisdom by providing all the answers, but rather, by modeling an openness to questions.

Maybe by experiencing wonder first-hand, and modeling a sense of wonder in the classroom, teachers can nurture an appreciation for the natural world, and foster a questioning stance that is often absent in current elementary science education. By modeling their lived experience of wonder rather than telling students what they want to know, teachers can foster in their students an awe of what is not yet known. This may shift value from the quantity of what is known to the potential of what there is to know. In alignment with Gadamer's thinking, maybe children can maintain the mindset the most important knowledge is not what is known, but what is left to learn. A teachers' ability to facilitate lived experiences of wonder in students may cultivate a stronger connection to the natural world, and a lifelong curiosity about what is left to learn. 


\section{References}

Allen-Collinson, J. \& Leledaki, A. (2015). Sensing the outdoors: a visual and haptic phenomenology of outdoor exercise embodiment. Leisure Studies, 34(4), 457-470.

Aoki, T. T., Pinar, W., \& Irwin, R. L. (2004). Curriculum in a new key: The collected works of Ted T. Aoki. Lawrence Erlbaum Associates, Publishers.

Aoki, T. T. (1993). Legitimating lived curriculum: Towards a curricular landscape of multiplicity. Journal of Curriculum and Supervision, 8(3), 255-268.

Carson, R. (1998). The sense of wonder. Harper Collins.

Foran, A., \& Saevi, T. (2012). Seeing pedagogically, telling phenomenologically: Addressing the profound complexity of education, Phenomenology \& Practice, 6(2), $50-64$.

Foran, A. \& Olson, M. (2012). Seeking pedagogical places. In N. Friesen, T. Saevi \& C. Henriksson (Editors). Hermeneutic Phenomenology in Education: Method and Practice. Sense Publishers.

Foran, A. (2008A). Teaching outside the school. Saarbrüchen, Germany. VDM Verlag Publishers.

Foran, A. (2008B). An outside place for social studies. Canadian Social Studies, 4l(1). Fall.

Foran, A. (2005). The experience of pedagogic intensity in outdoor education. Journal of Experiential Education, 28(2), p. 147-163.

Forster, S. \& Lavie, N. (2014). Distracted by your mind? Individual differences in distractibility predict mind wandering. Journal of Experimental Psychology: Learning, Memory, and Cognition, 40(1), 251-260.

Gadamer, H. G. (2004). Truth and method (2nd rev. ed.). Continuum.

Hahn, T. N. (2015, April 8). Wake up to the revolution. Retrieved from http://mindfulnessbell.org

Heidegger, M. (1977). The question concerning technology and other essays. Harper \& Row.

Heidegger, M. (1994). Basic questions of philosophy. Indiana University Press.

Heidegger, M. (1996). Being and time. State University of New York Press. 
Howarth, J. M. (1995). The crisis of ecology: A phenomenological perspective. Environmental Values, 4(1), 17-30.

Hung, R. \& Stables, A. (2008). Can we experience nature in the lifeworld? An interrogation of Husserl's notion of lifeworld and its implication for environmental and educational thinking. Indo-Pacific Journal of Phenomenology, 8(Special Edition), 1-8.

James, S. (2002). Heidegger and the role of body in environmental virtue. Trumpeter, $18(1), 1-9$.

Mayer, F. S., \& McPherson Frantz, C. (2004). The connectedness to nature scale: A measure of individuals' feeling in community with nature. Journal of Environmental Psychology, 24, 503-515.

Merleau-Ponty, M. (1962). Phenomenology of perception. Routledge.

National Research Council. (2012). A framework for K-12 science education: Practices, crosscutting concepts, and core ideas. Committee on a Conceptual Framework for New K-12 Science Education Standards. Board on Science Education, Division of Behavioral and Social Sciences and Education. The National Academies Press.

Online Reference Dictionary (2014). Retrieved from http://dictionary.reference.com/

Orr, N., Wagstaffe, A., Briscoe, S., \& Garside, A. (2016). How do older people describe their sensory experiences of the natural world? A systematic review of the qualitative evidence. BMC Geriatrics, 16(116). doi: 10.1186/s12877-016-0288-0

Parks, E. L., Kim, S., \& Hopfinger, J. B. (2014). The persistence of distraction: A study of attentional biases by fear, faces, and context. Psychonomic Bulletin \& Review, 21(6), 1501-1508.

Russell, H. R. (2001). Ten-Minute Field Trips. NSTA Press.

Thorburn, M., \& Marshall, A. (2014). Cultivating lived-body consciousness: Enhancing cognition and emotion through outdoor learning. Journal of Pedagogy, 5(1), 115132.

van der Schyff, D. B. (2010). The ethical experience of nature: Aristotle and the roots of ecological phenomenology. Phenomenology \& Practice, 4(1), 97-121.

van Manen, M. (2014). Phenomenology of Practice: Meaning-Giving Methods in Phenomenological Research and Writing. Left Coast Press. 